\title{
EU FloodEx 2009: an analysis of testing international assistance during a worst credible flood scenario in the North Sea area
}

\author{
R. J. J. Beerens ${ }^{1}$, B. Kolen ${ }^{2,3} \&$ I. Helsloot ${ }^{3}$ \\ ${ }^{I}$ Research Department, Netherlands Institute for Safety NIBRA, \\ The Netherlands \\ and Department of Fire Safety Engineering and Systems Safety, \\ Lund University, Sweden \\ ${ }^{2}$ Water and Safety Department, HKV Consultants, The Netherlands \\ ${ }^{3}$ Department of Public Administration and Organisation Science, \\ VU University, The Netherlands
}

\begin{abstract}
This paper discusses a case study example of testing international disaster response assistance within the European Union during a worst credible flood scenario in the North Sea area. It describes and evaluates the processes of requesting and receiving international assistance and the field operations with responding international teams during an exercise for large scale flooding ('EU FloodEx 2009'). It also discusses some of the issues identified during this exercise in the Netherlands. Additionally the characteristics of an (inter)national response in the case of flooding are related to various processes and the effectiveness after initiating them. For initiating and planning of these processes, the results of the exercise are reflected to availability of information during a threat or flood with regards to warning, decision making and response in case of uncertainty. The paper also introduces the structures, mechanisms and teams at the disposal of the Dutch and EU flood response community. It ends by discussing some experiences of 'EU FloodEx 2009' to improve the design of the EU response system and future exercises by implementing the lessons identified.

Keywords: flood response, exercise, international disaster response, evacuation, FloodEx.
\end{abstract}




\section{Introduction}

Disasters such as flooding may severely disrupt or overwhelm not only the local rescue and medical resources but even one or more (local) governments [1] thus requiring a large scale (inter)national response to be mobilised. Examples of where this has occurred include Hurricane Katrina, the Indian Ocean Tsunami and, most recently, the Haiti earthquake. This paper discusses a case study example of testing this kind of large-scale international disaster response assistance within the European Union (EU) in the case of a worst credible flood scenario in the North Sea area. In preparing and coordinating such an international response two important elements need to be considered in order to make the response effective and efficient: Firstly, the kind of disaster (suddenonset and slow-onset) is of great importance, secondly, the local and national capacities to cope with the impact of a disaster need to be addressed [2].

\subsection{Flooding}

Flooding, as a natural hazard, can occur in many different forms that cannot always be prepared for in advance. Although the probability for flooding can decline because of preventive measures, flood risk cannot completely be eliminated by building dykes or taking other precautionary measures. Another related issue is that floods can occur in many different types (as flash floods, storm surges, river floods [3]) each with their own characteristics, requiring different preventive actions. The type of flood also influences the time to prepare for and respond to it; however in this article we focus on flooding caused by extreme storm surge as this was the basis for the exercise discussed below. In this case, before the onset of the flood, forecasts are available that show the probability for flooding and preparative measures can be taken.

From a historical point of view, the Netherlands has focused primarily on flood prevention [4], resulting in a flood defence system with the highest safety standards in the world. The consequences of flooding, in terms of economic and social damage and casualties, could be enormous. An evaluation of the water safety policy in $2004[5,6]$ showed that the Netherlands is not prepared for an extreme flood event. This being the case, the need to improve preparation for disaster management has been addressed by the Dutch Government [7, 8]. Emergency planning for flood response and especially large-scale evacuation were drafted by the national and regional authorities [9]. The rationality for this may be found in risk analyses for The Netherlands made up in 2008 [10] and 2009 [11] which showed flooding to be the disaster type with the most extreme consequences (catastrophic) although the probability is low (highly unlikely).

\subsubsection{Disaster management in the case of flooding}

Disaster management planning for flooding in (for example) the Netherlands and the North Sea region is based on scenarios of varying scales. It requires dealing with uncertainties such as threat recognition and assessment, decision-making (including which strategies to choose, based on possible operational strategies) 
and movement to the safest place possible, given the circumstances. The primary goal is to save lives, the secondary goal to limit damage. For decision-making several strategies can be distinguished. All these strategies require operational planning, decision-making, resource identification and management, communication and traffic management on a (inter)national scale [1].

The decision-making process related to these scenarios is influenced by short response times, possible life and death situations and a huge economic impact. Decision-making also means coping with uncertainties, pressure from public and media and fear for false alarms or missed calls. The most likely scenarios that were developed for decision-making in advance of a disaster are used as a guideline during the response and do not always give a clear overview of what really will happen; therefore too many uncertain variables are involved in the scenario building process. The scenarios however can be adjusted afterwards based on a review of data, but during the decision-making process for response operations little information is available to fully adjust the scenario that was used to prepare and respond and there is a discrepancy between scenario and reality. It is therefore important for a country to consider how much has to happen before international response is needed based on the information they receive.

\subsection{International response to disasters}

In the initial stages after any large scale disaster most of the response is provided and coordinated at a local level by local emergency authorities and bystanders [13-15] but when the disaster exceeds the State's response capacity and time passes by, international response could mitigate its effects and perform various tasks to assist the community. The international response is compiled of additional resources aiming to increase the local capacities and bring in specific disaster-related resources and humanitarian aid in order to save lives and prevent further damage. However if an affected country is not prepared for this kind of response, chaos may be created by the huge amount of (international) people and equipment $[16,17]$. To be able to use international assistance a country has to be flexible enough to expand readily as additional resources are added. This helps to match the levels of demand posed by an escalating event [18].

When international response is dispatched to a country the organisation of response and the response time need to be considered to prevent the abovementioned chaos. It is therefore important that all planning and response begins with the local capabilities and resources that later may be supplemented by extra community and international capabilities and resources. In many cases countries are not explicitly prepared for incoming international disaster response [18]. In addition, one should consider that individuals who normally are responsible for the coordination of disaster management systems on a local level are suddenly required to take on board extra resources from abroad that they may not understand.

Another important element that supports the need for being prepared for incoming international disaster assistance is the response time that is available; time is crucial for victim survival and preparedness can decrease this time [19, 20]. External resources need time to reach local responders [18]. In sudden on- 
set (natural) disasters such as earthquakes or flash floods, this response time to save lives is measured in hours [21]. However, the vast majority of possible lifesaving rescues $(90 \%)$ occurs within the first 24 hours after a disaster and are mostly accomplished by local personnel using simple tools, as was illustrated in the case in the Indian Ocean Tsunami [2, 22]. The mobilisation times of international disaster teams are up to 24 hours, so these teams will start arriving after the initial stages of the disaster management as shown in figure 1 below from the Indian Ocean Tsunami response in Aceh [23].

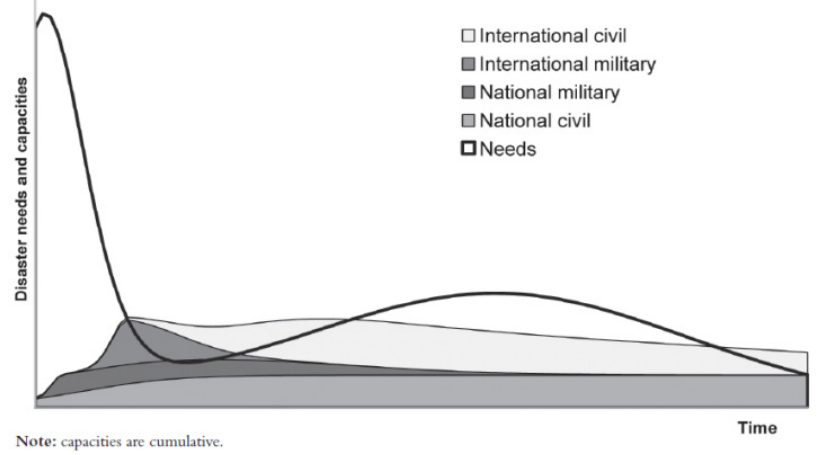

Figure 1: National and International Capacities in Aceh following the Indian Ocean Tsunami [23].

\subsubsection{International response systems}

When responding on an international level a great effort is being taken to structure international response by various organisations with their own response system so that it should minimize chaotic situations. Currently, EU countries can rely on help from various governmental organizations requested through bilateral agreements or via for example the EU Community Mechanism for Civil Protection, the North Atlantic Treaty Organization (NATO) or the United Nations (UN) response systems. Although various systems can be set up, they are at present not all specifically designed for, or evaluated on the basis of, delivering assistance in EU-countries because of the low-probability high-risk scenario of large scale disasters in the EU area. The EU however is developing a system using various modules that can be mobilized in for example flood situations. Examples of these modules are high capacity pumps and water rescue modules [24].

The legal basis for the EU provision of assistance lies in the Civil Protection Mechanism [25]. An important mechanism in coordinating the EU disaster response is the EU Monitoring and Information Centre (MIC). For NATO, the basis for assistance and the provision of emergency disaster relief lies in the principles which apply within the Euro-Atlantic Partnership Council (EAPC). The practical coordination of this is done by the Euro-Atlantic Disaster Response Coordination Centre (EADRCC). The UN uses resolutions that emphasise the importance of international disaster response and preparedness [26, 27]. Their 
operational coordination is done via the Office for Humanitarian Affairs (OCHA). It should be noted that the abovementioned efforts are based on universal dialogues and that in all of these frameworks the individual Nations fully keep their own sovereignty and are able to respond to a disaster in a way they believe is best.

As stated above, the kind of disaster and the local and national capacities required to cope with the impact of a disaster are important issues to be addressed before an international response can effectively be mobilized. Therefore the disaster scenario, the organisation of the response and timeliness should be considered when preparing for and conducting such an international disaster response. It is these elements that are reviewed in relation to the 'EU FloodEx 2009' case as described in the next section to emphasise their importance.

\section{Exercise 'EU FloodEx 2009'}

The international exercise 'EU FloodEx 2009' aimed to test the recently developed procedures concerning incoming foreign assistance in the Netherlands during a worst credible flood. For the exercise a scenario was developed that described the development of the threat starting 6 days (D-6) before the flood (D-0) up to a few days after the flood. The scenario was based on:

- Worst credible flood scenario for the West coast of the Netherlands [28]; The size and impact of the flood in North Holland is adapted to fit to the exercise goals. Worst Credible Floods give an upper limit of flooding scenarios that is still considered realistic and credible by experts, and that can be used for emergency planning in addition to other less extreme scenarios [28]. For the exercise scenario it was decided that the worst-case flood scenario should be chosen and that it will focus on a situation with shortage of almost all available means.

- Evacuation using advanced traffic management (using the national concept of evacuation) [29]

- National emergency planning, using the National Crisis Plan for Flooding [30], National Operation Plan for Evacuation [31] and the Guideline for Extreme Water Level and Storm Surge [32, 33].

The procedures that were developed for structuring and organising international disaster response are written down in the Dutch "Manual for incoming foreign assistance". This Manual was used to establish a national response structure that is able to accommodate incoming international response teams into the ongoing National disaster response operations. An overview of the most important mechanisms and their role within the operational response structure that was designed for FloodEx is given in table 1. This structure is based on guidelines and policy documents provided by the UN, NATO, EU and related organisations. However FloodEx was specifically based on the European Community Civil Protection Mechanism, with the overall objective to improve and train existing procedures for alerting, mobilising and dispatching international emergency services in the event of a serious flood. 
The guiding assumption for the design of the response structure is that the efforts to deal with the disaster using only Dutch resources are insufficient (quantitatively and/or qualitatively), as a result of which foreign assistance is needed. In that situation the Netherlands will retain control (either at national or regional level) of the response. The Netherlands can thereby receive support from other countries, the exercises focused on EU member states. However, the manual is an operational guideline and does not involve the political decision making process that is also of importance during the request of foreign assistance.

Table 1: $\quad$ EU FloodEx 2009 response mechanisms.

\begin{tabular}{|c|c|}
\hline Mechanism & Description \\
\hline $\begin{array}{c}\text { Reception and Departure } \\
\text { Centre (RDC) }\end{array}$ & $\begin{array}{c}\text { The arrival and departure location. This is a gathering place } \\
\text { where the foreign assistance units receive their initial } \\
\text { instructions after arrival and registration. }\end{array}$ \\
\hline $\begin{array}{c}\text { EU coordination team } \\
\text { A Coordination team that supports the LEMA with the } \\
\text { deployment of foreign assistance teams. This coordination team } \\
\text { offers support to the Dutch authorities in the disaster relief in } \\
\text { terms of the deployment of the foreign assistance units. }\end{array}$ \\
$\begin{array}{c}\text { On Site Operations and } \\
\text { Coordination Centre } \\
\text { (OSOCC) }\end{array}$ & $\begin{array}{c}\text { A Coordination centre for the deployment of foreign assistance } \\
\text { teams. This coordination centre offers support to the Dutch } \\
\text { authorities in the disaster relief in terms of the deployment of the } \\
\text { foreign assistance units. }\end{array}$ \\
\hline $\begin{array}{c}\text { Local Emergency and } \\
\text { (LEMA) }\end{array}$ & $\begin{array}{c}\text { This is the international term for the (local) authority responsible } \\
\text { for dealing with the disaster (control of the disaster relief). }\end{array}$ \\
\hline $\begin{array}{c}\text { On-Site Commander } \\
\text { (OSC) }\end{array}$ & $\begin{array}{c}\text { This is the international term for the commander (operational } \\
\text { leader) at the place of the incident }\end{array}$ \\
\hline $\begin{array}{c}\text { Base of Operations (BoO) } \\
\text { Base camp for the foreign assistance units. This is the base camp } \\
\text { where the foreign units have gathered their personnel and from } \\
\text { where they depart for the location where they are deployed }\end{array}$ \\
\hline
\end{tabular}

\subsection{Excercise Elements}

The exercise was roughly divided into two major parts, with the supporting scenario describing a starting situation for each of these parts. The times between the exercise parts are integrated into the lead-in scenario, however, they were not exercised in real time due to the limitations of exercise playing time. Therefore based on assumptions within the scenarios, the following activities were carried out:

1. Command Post Exercise (CPX); A two day international exercise from D-1 to D-0 (the flood starts at midnight) for national decision makers to apply for and respond to international assistance.

2. Field Exercise (FE); A four-day international exercise starting at D+2 with focus on the aspects of cooperation under Community Civil Protection Mechanism after a large-scale flooding. The overall objective was to train and improve existing procedures of alerting, mobilizing and dispatching civil protection intervention and expert teams in case of disasters. 


\subsubsection{Focus of the paper}

This paper discusses a selection of lessons identified during the different parts of the exercise. The lessons are discussed based on the experiences documented in various after-exercise reports and the scenario as described below [34, 35]. In this paper these findings are related to the elements that were described in the previous paragraph. Specifically:

- The Command Post Exercise in dealing with the timeliness of requesting national and international assistance in the context of uncertainties that should be considered during a threat or crisis.

- The Field Exercise in dealing with the Operational EU disaster response organisational structures and timeliness in the immediate aftermath of a flood disaster.

A selection of observations made during the abovementioned exercise parts are discussed in relation to the previously mentioned elements of disaster response in case of large scale flooding to improve the design of the EU response system and future exercises by implementing the lessons learned.

\subsection{Scenario}

The development of the scenario used for FloodEx was based on the experiences of the flood in 1953, the Dutch exercise 'Waterproef' and scenarios as 'Worst Credible Flood' and Evacuation in The Netherlands, H19 in United Kingdom and expert opinions [28, 30].

The scenario describes a storm surge in the North Sea, in which the area is hit by a severe depression with extreme wind velocities, coinciding with spring tides. This combination of natural events leads to extreme high water in the United Kingdom and The Netherlands and high tide in Germany that causes high water levels in estuaries.

\subsubsection{Scenario: Development of the threat for flooding}

The scenario starts when meteorological and flood-forecasting experts detect the possibility for extreme weather (and flooding). The actual weather at that time, and the forecast for the following few days are 'weather as usual'. Only experts are able to clarify why some conditions above the Atlantic Ocean that might cause extreme weather in the near future. At this moment it is foreseen that a flooding could occur over 5 to 6 days because of the storm surge and high tide. The probability for flooding is low, about 5\%. The development and direction of the depression and the combination with the local tide on sea is very uncertain. Flooding can only occur in very specific conditions as extreme wind above the North Sea region with direction northwest.

In the following days the probability slowly increases to $15 \%$ at D-4. At D-1, at the start of the storm, the probability further increased up to $40 \%$ in the morning and $55 \%$ in the afternoon. These are akin to a genuine scenario.

The exercise scenario postulates that the threatened area after detection (D-6) is the entire North Sea area which is flood prone due to a storm surge (United Kingdom, Denmark, Germany, The Netherlands and Belgium). The exercise also suggests that the Netherlands and the United Kingdom may experience an impact 
that exceeds the flood of 1953. For the Northern part of Germany there was a high risk of overtopping of dikes and river flooding caused by extreme seawater levels. The development of the flood in The Netherlands after the dike breach for the first day is shown in Figure 2.

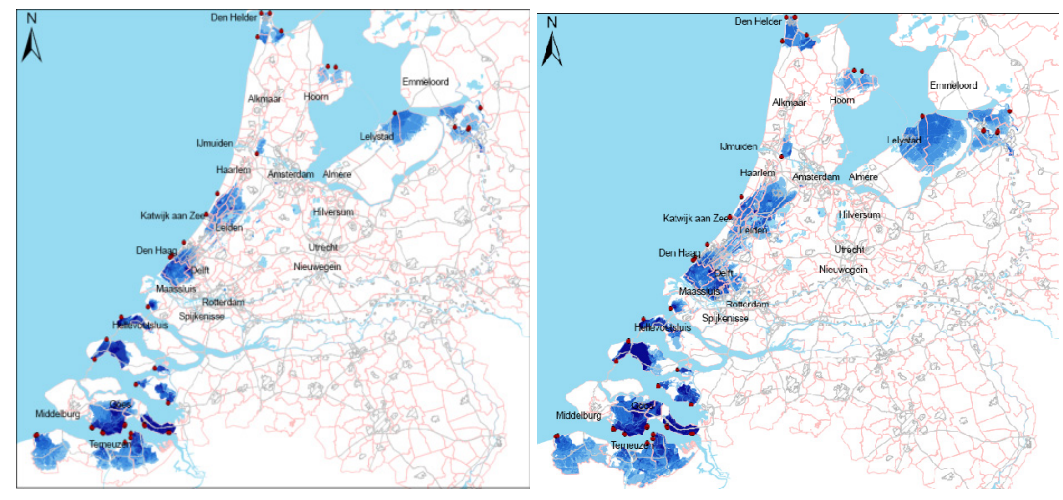

Figure 2: Development of the flood.

\subsubsection{Scenario: decisions, measures and consequences}

After detecting the possibility of extreme wind (by meteorological offices) and a possible flood situation (by Flood Forecasting Centres) on D-6, the crisis centres will be alarmed. The crisis structure of local, regional and national authorities is started up. As a result, the national government gives instructions and guidance to the regions in order to prepare evacuation planning. In addition, they set out guidelines for decision-making and business continuity in the threatened area.

National organisations give instruction and guidance to the regional and local organisations to make a decision about a preventive or vertical evacuation based on the consequences in the whole affected area. At D-6 national organisations prepare themselves for possible decisions for evacuation on D-4. All partners develop an overall strategy combining national and regional planning and assistance (within a country).

At D-4 the first decisions are made for evacuation of the most vulnerable, measures for infrastructure protection and business continuity. Decisions to evacuate those who are self-supporting are postponed a day to wait for the development of the threat.

At D-3 the probability has not declined so the evacuation of the selfsupporting is initiated. Some people self-evacuate and leave the threatened area, whilst others prepare themselves inside their homes or in relief centres for the public (such as community centres). National and regional traffic management plans are implemented to facilitate the evacuation. After D-3 regional authorities start emergency planning for possible rescue operations after a flood.

The time available for proactive or precautionary evacuation is approximately 33 hours after the decision is made, which includes the implementation of traffic management measures for evacuation. It will not be possible for all people to evacuate ahead of the predicted floods due to the limited capacity of 
infrastructure. Those not evacuated (which may include local businesses) are assumed that they will support themselves for 72 hours starting from D-1. At midnight of D-1, overloading on the highway networks hinders the evacuation. Additionally, during D-1, extreme wind speed makes outdoor areas too unsafe to travel through. According to the scenario, 1.4 million people succeed in evacuating the affected areas; however, there are an equal number still is in the flood zone. These people are either in a relief centre, in their homes, or elsewhere.

The scenario continues at D+2 and takes place at the Field Exercise locations in Noord Holland. Several parts of the west side of the Netherlands are flooded. As stated in the exercise description, it is assumed that the Netherlands will retain control over the response and therefore the local emergency services and the national disaster organisation are still (if partially) functioning. There is however a shortage of operational capacities and adequate information for defining needs assessments. Because of the scale of the flood, a comprehensive assessment of the need for help has not been carried out everywhere in the flooded zone and it is difficult to define the precise capabilities needed. However the local emergency management authority (LEMA) and International EU Coordination Team are coordinating the deployment of incoming foreign units on $\mathrm{D}+2$ together with Dutch units at various locations in the northern part of Noord Holland (the Amstelmeer, Groote and Kleine Vliet and the Alkmaardermeer) as shown in figure 3. During their deployment they are required to conduct various search and rescue activities and pumping operations. Their mission lasted for about two days according the scenario.



Figure 3: Overview of exercise locations.

\section{Lessons identified and discussion}

During FloodEx, data was collected using teams of observers. Most of the observers were specially trained to use the same methodological approach in observing the various parts of the exercise based on predefined objectives. Their 
observations were qualitatively judged and analysed using the policy and guidelines about incoming international disaster response assistance. The information in this chapter is derived from these evaluations $[34,35]$ and due to the limitations of this paper, a selection were made based on the elements described in the introduction.

Observations suggest that the worst-case scenario designed for this exercise was modified from a real-scenario. The Field Exercise demonstrated that the scenario was not a realistic disaster situation as times and locations for the operations were limited and reduced. For example, the exercise took place on two specific locations in a country that was heavily affected by the flood and the focus was on these locations while the rest of the Netherlands was 'ignored '. Nevertheless, lessons can be learned if the evaluation outcomes of the exercise play that was conducted.

\section{Scenario used for requesting assistance}

The dynamics offered for decision making on requesting assistance were based on assumptions of the threatened area, figures for rescue operations and the population that has to be rescued or that helps themselves. The exercise play showed differences in the command and control structure of the operation and did not account for possible uncertainties in the assumptions of the rescue operation or population numbers. For example, people were considered to be self-supporting for 72 hours. No consideration was given to the effects of earlier or later rescue. Also assumptions about travel times of equipment, number of people that has to be rescued, break down of equipment were not questioned and strictly predefined in the exercise scenario.

Although this was an exercise situation and in reality others might ask for these alternatives, it is recommended that alternatives and consequences of uncertainties explicit into account in planning documents be taken into account. This could contribute more positively to flexible planning procedures and the possibility to decision making in advance prepared strategies.

\section{Moment of requesting assistance}

The first request to mobilise international assistance was given at D-1 in the afternoon. At this moment the occurrence of the disaster was almost certain (55\%). The first request for assistance was given to inform other EU member states about the situation and to await the upcoming final confirmation of the request. The final confirmation for assistance was done at D-0 after the dike breach. After this request, EU member states have to offer assistance and agreements have to be made. Approximately, it will take two days for the assistance to arrive.

After the request for international request for assistance has been made, it takes some time ( 2 days) for mobilisation to the affected country. Additionally, all national resources were already put in place and fully used. They were mobilised from D-6, however, at D-4 and the whole country was dealing with significant evacuation of the coastal areas. The available information, even with regards to the uncertainty, was enough to mobilize all resources inside a region but not enough to mobilize the resources in other states. 
From the perspective of minimizing loss of life, it would be optimal to call for assistance at the same moment national resources are mobilized. Other, not affected, EU member states can make agreements, transport arrangements and prepare resources for delivering assistance in good time. Transportation can then start directly after the onset of the disaster and offer assistance more early, ideally during the first day after the disaster. Information of the threat is already available to the affected public and local authorities, therefore it could be suggested that the EU could be proactive in using this information and contact members states who are anticipating a possible call for support.

Time needed for effective assistance

During FloodEx, it was observed that some teams had very long travel times by road, up to and more than 48 hours for the Estonian team as one example, and that this lead to a delay in operations as this part of the exercise started at $\mathrm{D}+2$. In a real disaster, choosing other means of transport should be considered to reduce travel times and foster early deployment.

\section{Command and control}

Because there may be various international disaster response systems that could be used, it may sometimes unclear what requirements used to underpin the coordination of this aid if one is not prepared or familiar with local command structures and protocols. During FloodEx, it became clear that at a regional level there was no clarity about the on-site command (OSC) structure and two different approaches were chosen:

1. "Modular Approach": Assisting foreign teams establish their own communication network and operational plan for their area of responsibility. This lead to little interaction with the Dutch command and response units working in adjacent areas. In terms of the overall coordination of the rescue efforts this might be considered suboptimal. A related issue was that the on site command (OSC) could not provide specific and accurate information, as this was not available. This influenced the accuracy of the response as there was little information about the various operations that needed to be performed by the foreign modules and they were is some cases waiting for further orders to perform their tasks.

2. "Resource-driven Approach": Dutch entities such as Fire Services, "Reddingsbrigade" and medical services used the resources of the Foreign Teams based on their assessment of the local situation. Choosing this approach led to the "international aid modules" being fragmented based on the tasks that needed to be performed. Choosing this approach showed the underutilisation of the resources and capabilities of the convoy/teams, as, due to the availability of information, the OSC did not have a good overview of the capacities and capabilities of the modules.

It is therefore concluded that the regional commanders must have good knowledge about the foreign assistance unit's capacities and capabilities, and that incoming assistance team leaders are encouraged to work closely with them 
to jointly identify the best solutions to local problems. Also the national and international systems could be better linked to each other in order to create a transition when scaling up that is smooth and effective and contributes to a timely response as stated earlier. For example local Dutch teams should be more trained to cooperate with international teams as this might be likely the case in disasters such as the one described in the scenario.

Reflection: reality of the exercise

EU FloodEx 2009 was a large scale exercise but compared to a real large scale disaster still minor. If a real flood disaster happens in that area one can doubt if the local emergency services will be able to function normally and that it can give clear guidance to the international teams.

During the Field Exercise little attention was paid to the citizen's response in this kind of disaster. It is likely to assume that in a real flood disaster this will be the case and that teams need to cooperate with civilians, emergent groups as well as local emergency responders in order to fulfil its tasks.

In a real flood disaster it is doubtful if all citizens will, or can be identified and rescued within a short timeframe. The disaster response might last longer than the exercised two days revealing other issues such as supply of the teams, tiredness, resource constraints, humanitarian aid and more. In addition neighbouring countries in the area might request a large amount of resources that are scarcely available. However the exercise successfully contributed to gaining more useful insights in the various processes and mechanisms that are set in place in case of international disaster response assistance. In the future these insights can contribute to the design of a more effective (inter-)national disaster response assistance system.

\section{Acknowledgements}

The authors would like to thank the 'EU FloodEx 2009' Project Team for sharing their experiences, knowledge and information. In particular Mr. Peter Glerum is thanked.

\section{References}

[1] Kolen, B., Holterman, S., van Zuilekom, K.M., Friso, K. \& Helsloot, I., If things do go wrong: influence of road capacity on mass evacuation in the event of extreme flooding in The Netherlands., International Conference Evacuation Management 2009, Delft, 2009.

[2] Tsunami Evaluation Coalition (TEC), Joint evaluation of the international response to the Indian Ocean tsunami: Syntesis Report, TEC: London, pp. 40-65, 2006.

[3] Jonkman, S.N., Loss of life estimation in Flood risk assessment. Theory and applications PhD Thesis: Delft University of Technology, 2007. 
[4] Van de Ven, G.P., Man-Made Lowlands, History of Water Management and Land Reclamation in the Netherlands. International commission on irrigation and drainage (ICID): Utrecht, 2004.

[5] RIVM, Dutch dikes and risk hikes. A thematic policy evaluation of risks of flooding in the Netherlands, RIVM: Bilthoven, 2004.

[6] Ten Brinke, W.B.M., Bannink, B.A. \& Ligtvoet, W., The evaluation of flood risk policy in The Netherlands. Journal on Watermanagement, 151(4), pp. 181-188, 2008.

[7] Ministry of Transport Ministry of the Interior and Kingdom Relations, Public Works and Water Management, Strategies for flood disaster control along the rivers Rhine and Meuse (in Dutch). Ministry of Transport Ministry of the Interior and Kingdom Relations, Public Works and Water Management: Den Haag, 2005.

[8] Ministry of Transport Ministry of the Interior and Kingdom Relations, Public Works and Water Management, Cabinet standpoint disaster management floods (in Dutch). Ministry of Transport Ministry of the Interior and Kingdom Relations, Public Works and Water Management : Den Haag, 2006.

[9] Taskforce Management Flooding (TMO), Final Report (Rapport van bevindingen, in Dutch). TMO: Den Haag, 2009.

[10] Ministry of the Interior and Kingdom relations, National Security, National risk assessment 2008 (in Dutch). Ministry of the Interior and Kingdom relations: Den Haag, 2008.

[11] Ministry of the Interior and Kingdom relations, National Security, National risk assessment 2009 (in Dutch). Ministry of the Interior and Kingdom relations: Den Haag, 2009.

[12] Ministry of Transport Ministry of the Interior and Kingdom Relations, Public Works and Water Management, Reaction Dutch Cabinet on results Task Force Management Flooding (in Dutch). Ministry of Transport Ministry of the Interior and Kingdom Relations, Public Works and Water Management: Den Haag, 2009.

[13] Yang, Y., The 9/21 earthquake in Taiwan: a local government disaster rescue system. Disasters, 34(1), pp.112-136, 2010.

[14] De Ville de Goyet, C., Stop propagating disaster myths, Lancet, 356(9231), pp. 762-764, 2000.

[15] Helsloot I. and Ruitenberg, A., Citizen response to disaster; a review of literature and some applications, Journal of Contingencies and Crisis Management, 12 (3), pp. 98-111, 2004.

[16] Chiu, W. T., Arnold, J., Shih, Y. T., Hsiung, K. H., Chi, H. Y., Chiu, C. H., Tsai, W. C. \& Huang, W. C., A survey of international urban search-andrescue teams following the Ji Ji earthquake. Disasters. 26, pp. 85-94, 2002.

[17] Romundstad, L., Sundnes, K. O., Pillgram-Larsen, J., Roste, G. K. \& Gilbert, M. : Challenges of major incident management when excess resources are allocated: experiences from a mass casualty incident after roof collapse of a military command center. Prehospital Disaster Med., 19, pp. 179-184, 2004. 
[18] Perry, R.W., Incident management systems in disaster management. Disaster Prevention and Management, 12(5), pp. 405-412, 2003.

[19] Barbera, J.A., and Macintyre A., Urban search and rescue, Emerg Med Clin North Am. 14, pp. 399-412,1996.

[20] Barbera J. A. and Cadoux, C. G., Search, rescue, and evacuation. Crit Care Clin. 7, pp. 321-337, 1991.

[21] Katoch, A., International Natural Disaster Response and the United Nations, United Nations Office for the Coordination of Humanitarian Affairs - Field Coordination Support Section: Geneva, 2003.

[22] Macintyre A. G., Barbera, J. A. \& Smith, E. R., Surviving collapsed structure entrapment after earthquakes: a "time-to-rescue" analysis. Prehospital Disaster Med., 21, pp. 4-17, discussion 18-9, 2006.

[23] Cosgrave, J. and Telford, J. The international humanitarian system and the 2004 Indian Ocean earthquake and tsunamis, Disasters, 31(1), pp.1-28, 2007

[24] European Commission, Commission Decision 2008/73/EC: Decision of the Commission of 20 December 2007 to amend decisions 2004/277/EC and 2007/779/EC. EU Commission: Brussels, 2007.

[25] European Council, EU Council Decision establishing a Community Civil Protection Mechanism 2007/779/EC, EU Council: Brussels, 2007.

[26] United Nations General Assembly, UN General Assembly Resolution 57/150 of 16 December on the Strengthening the effectiveness and coordination of international urban search and rescue assistance. United Nations: New York, 2002.

[27] United Nations General Assembly, UN Resolution 46/181 of 19 December on the Strengthening of the coordination of humanitarian emergency assistance of the United Nations. United Nations: New York, 1991.

[28] Ten Brinke, W.B.M., Kolen, B., Dollee, A., van Waveren, H. \& Wouters, C.A.H., Contingency planning for large-scale floods in the Netherlands, Journal of Contingencies and Crisis Management, (in press), 2010.

[29] Wegh, E., National Concept Traffic Management for exercise Waterproef (in Dutch). Ministry of Transport, Public Works and Water Management: Utrecht, 2008.

[30] Ministry of the Interior and Kingdom relations, National Crisis Plan Extreme Water Levels and Flooding, Communication Strategy (in Dutch), Ministry of the Interior and Kingdom relations: Den Haag, 2008.

[31] National Operations Centre (LOCC), Concept National Operational Plan evacuation for exercise Waterproef (in Dutch), LOCC: Driebergen, 2008.

[32] Ministry of Public Works and Water Management and Ministry of Transport, Emergency plan "Extreme water level and storm surge" Guideline for a national approach (in Dutch), Ministry of Public Works and Water Management and Ministry of Transport: Den Haag, 2008.

[33] Ministry of Public Works and Water Management and Ministry of Transport, National situational report flooding, roles and responsibilities of the National Commission of Flooding. HKV lijn in water: Lelystad, 2009. 
[34] National Operations Centre (LOCC), EU FloodEx 2009: Field Exercise Evaluation Report, The Netherlands Institute for Safety NIBRA: Arnhem, 2009.

[35] National Operations Centre (LOCC), EU FloodEx 2009: Final Technical Report, Landelijk Operationeel Coördinatie Centrum (LOCC): Driebergen, 2009. 